\title{
Characterization and quantification of biochar alkalinity
}

Rivka B. Fidel*, David A. Laird, Michael L. Thompson, and Michael Lawrinenko

Department of Agronomy, Iowa State University, Ames, Iowa, 50011

*Corresponding Author

E-mail: rfidel@iastate.edu. Tel.: 19144133505

Rivka Fidel

2501 Agronomy Hall

Iowa State University

Ames, Iowa, 50011

\section{ABSTRACT}

Lack of knowledge regarding the nature of biochar alkalis has hindered understanding of $\mathrm{pH}-$ sensitive biochar-soil interactions. Here we investigate the nature of biochar alkalinity and present a cohesive suite of methods for its quantification. Biochars produced from cellulose, corn stover and wood feedstocks had significant low-pK $\mathrm{a}_{\mathrm{a}}$ organic structural $\left(0.03\right.$ to $\left.0.34 \mathrm{meq}^{-1}\right)$, other organic (0-0.92 meq $\left.\mathrm{g}^{-1}\right)$, carbonate $\left(0.02-1.5 \mathrm{meq} \mathrm{g}^{-1}\right)$, and other inorganic $\left(0-0.26 \mathrm{meq} \mathrm{g}^{-}\right.$

${ }^{1}$ ) alkalinities. All four categories of biochar alkalinity contributed to total biochar alkalinity and are therefore relevant to $\mathrm{pH}$-sensitive soil processes. Total biochar alkalinity was strongly correlated with base cation concentration, but biochar alkalinity was not a simple function of elemental composition, soluble ash, fixed carbon, or volatile matter content. More research is needed to characterize soluble biochar alkalis other than carbonates and to establish predictive relationships among biochar production parameters and the composition of biochar alkalis.

\section{KEYWORDS}

Biochar; alkalinity; $\mathrm{pH}$; functional groups; carbonate; organic 
Abbreviations FC = fixed carbon; VM = volatile matter; CEC = cation exchange capacity; XRF $=\mathrm{x}$-ray fluorescence; $\mathrm{XRD}=\mathrm{x}$-ray diffraction

\section{Introduction}

Biochars, the solid co-products of the pyrolysis biomass-to-bioenergy pathway suitable for use as a soil amendment (Lehmann et al., 2006; Schimmelpfennig and Glaser, 2012), are diverse materials with a wide range of chemical and physical properties (Brewer et al., 2011; Kloss et al., 2012; Singh et al., 2010; Wang et al., 2014). Application of biochar to soil can sequester carbon (C) by both increasing soil carbon directly and by increasing yields of biomass $\mathrm{C}$, but such benefits are dependent on properties of both the soil and the biochar. Biochar application has been shown to increase soil cation exchange capacity (CEC), water-holding capacity, nutrient retention, and $\mathrm{pH}$, and also to decrease soil bulk density and net greenhouse gas emissions from soil agroecosystems (Fidel, 2015; Joseph et al., 2010; Laird et al., 2010). However, the effects of biochar amendments on soils arise from many complex-interactive processes, often resulting in strongly context-specific and method-dependent results (Joseph et al., 2010; Simek and Cooper, 2002). Alkalinity is one of the most influential biochar properties, because changes in $\mathrm{pH}$ have cascading impacts on many soil processes, including nitrogen mineralization, mineral precipitation, ion exchange, and greenhouse gas emissions (Joseph et al., 2010; McCormack et al., 2013). Many studies have shown that biochar amendments increase and buffer soil $\mathrm{pH}$, but the nature of biochar alkalis, the influence of feedstock and biochar production conditions on biochar alkalinity, and the variability of alkali properties among biochars remain poorly understood (Xu et al., 2012; Yuan et al., 2011a, 2011b). A mechanistic understanding of how 
specific biochar alkalis interact with soil is therefore imperative to further $\mathrm{pH}$-related biochar research.

Four broad categories of biochar alkalinity have been identified in the literature: surface organic functional groups (as conjugate bases), soluble organic compounds (also conjugate bases of weak acids), carbonates (salts of bicarbonate and carbonate), and other inorganic alkalis, which may include oxides, hydroxides, sulfates, sulfides, and orthophosphates (Cheah et al., 2014; Singh et al., 2010; Yuan et al., 2011a). Distinguishing between these categories is essential to understanding the short- and long-term impacts of biochar on soil $\mathrm{pH}$, because soluble organic and inorganic alkalis contribute to short-term acid amelioration (Silber et al., 2010; Yuan et al., 2011b); while surface organic functional groups contribute to long-term soil $\mathrm{CEC}$ and $\mathrm{pH}$ buffering capacity (Mao et al., 2012). Furthermore, biochar surface functional groups with $\mathrm{pK}_{\mathrm{a}} \mathrm{s}$ close to that of typical soil pHs (5 to 7 ) will be the most active ion donators and acceptors in soil.

Widely differing methods for defining and quantifying biochar alkalinity categories have been employed in previous experiments, thereby confounding comparisons among studies (Dai et al., 2014; Singh et al., 2010; Wan et al., 2014; Yuan et al., 2011b; Yuan and Xu, 2011). Existing methods for determining total alkalinity include: (1) directly titrating a biochar-water slurry with $0.1 \mathrm{M} \mathrm{HCl}$ (Wan et al., 2014), (2) equilibrating biochar with $0.03 \mathrm{M} \mathrm{HCl}$ and titrating the extracts with $\mathrm{NaOH}$ (Yuan and $\mathrm{Xu}, 2011$ ), and (3) shaking biochar with $1 \mathrm{M} \mathrm{HCl}$ for $2 \mathrm{~h}$, followed by titration of extracts with $\mathrm{NaOH}$ (Singh et al., 2010). Determining carbonate alkalinity in biochars typically requires quantification of $\mathrm{CO}_{2}$ liberated during equilibration with $\mathrm{HCl}$ by using a manometer or $\mathrm{NaOH}$ trap. However, recommended $\mathrm{HCl}$ concentrations have varied from 1 to $4 \mathrm{M}$ and equilibration times have ranged from 1 to 5 days (Wan et al., 2014; Wang et al., 2014). The $\mathrm{NaOH}$ trap method was determined to be the most accurate for 
quantification of carbonates, but the effects of $\mathrm{HCl}$ concentration and equilibration time on carbonate and total alkalinity determination have not been examined (Wang et al., 2014). Silber et al. (2010) showed that the release of ions and neutralization of $\mathrm{H}^{+}$by biochar is both $\mathrm{pH}$ - and time-dependent, signifying total alkalinity and carbonate alkalinity should be measured under the same conditions to facilitate quantitative comparisons; however, no single study has done so. Lastly, most studies use Boehm titrations to quantify weak organic acid functional groups that are directly bonded to biochar surfaces. These functional groups can contribute to alkalinity when present as deprotonated conjugate bases. On the other hand, recent reports indicate that soluble alkalis can confound Boehm titration results (Fidel et al., 2013; Tsechansky and Graber, 2014). Although several studies have quantified one - and in some cases two - categories of biochar alkalinity (Chen et al., 2015; Chun et al., 2004; Dai et al., 2014; Tsechansky and Graber, 2014; Wan et al., 2014; Wang et al., 2014; Yuan et al., 2011b), no study has systematically investigated the relative abundance of all four categories of biochar alkalinity or considered method efficacy. Therefore, this study investigates the nature of biochar alkalis and presents a cohesive suite of methods for their quantification.

\section{Materials and Methods}

\subsection{Biochar preparation}

Given the diversity of biochars, a full analysis examining biochars produced from all possible combinations of feedstock and pyrolysis conditions is beyond the scope of this study. Hence, eight biochars produced at three temperatures $\left(300,500\right.$ and $\left.600^{\circ} \mathrm{C}\right)$ and by three processes (slow pyrolysis, fast pyrolysis, and gasification) were chosen to encompass the anticipated range of total alkalinity and alkalinity distributions for cellulosic and lignocellulosic feedstocks (Table 1). 
Slow pyrolysis biochars made from cellulose (Sigma Aldrich) and corn stover (Zea mays; harvested in Boone, IA) were pyrolyzed in a $\mathrm{N}_{2}$-purged muffle furnace. The muffle furnace temperature was first held at $105^{\circ} \mathrm{C}$ for 1 hour to remove any water present in the feedstock, then the furnace was heated to $100^{\circ} \mathrm{C}$ below the highest treatment temperature $\left(200^{\circ} \mathrm{C}, 400^{\circ} \mathrm{C}\right.$ or $500^{\circ} \mathrm{C}$ ) at $10^{\circ} \mathrm{C}$ per minute, and held at that temperature for 2 hours before increasing to the highest treatment temperature at $0.5^{\circ} \mathrm{C}$ per minute. The highest treatment temperature $\left(300^{\circ} \mathrm{C}\right.$, $500^{\circ} \mathrm{C}$, or $600^{\circ} \mathrm{C}$, see Table 1) was then maintained for 2 hours before the furnace was allowed to cool overnight under $\mathrm{N}_{2}$-purge. A hardwood slow pyrolysis biochar (HW5s), obtained from Royal Oak Enterprises, LLC (size \#10 charcoal, 0.5-2mm, http://royal-oak.com/), was produced using a traditional kiln. A mixed wood gasification biochar (MW6g), obtained from ICM, Inc. (http://www.icminc.com/), was produced using a auger bed gasifier at $550-650^{\circ} \mathrm{C}$ from a blend of primarily oak (Quercus spp.), elm (Ulmus spp.) and hickory (Carya spp.) woodchips with particle sizes $0.1-2000 \mathrm{~mm}$. Two fast pyrolysis biochars, RO5f and CS5f - produced from red oak wood (Quercus rubra) and corn stover (Zea mays) respectively at $500^{\circ} \mathrm{C}$ - were obtained from the Center for Sustainable Energy Technologies at Iowa State University. Both of the fast pyrolysis biochars were produced in a fluidized bed reactor that used $\mathrm{N}_{2}$ as a carrier gas and sand particles ( $0.5 \mathrm{~mm}$ average particle diameter) as fluidization media (Pollard, 2009; Pollard et al., 2012). These fast pyrolysis biochars were sieved to $<0.50 \mathrm{~mm}$ to minimize the influence of sand particles. All slow pyrolysis and gasification biochars were ground to $<0.50 \mathrm{~mm}$ to minimize the influence of particle size on chemical analyses.

\subsection{Biochar $p H$}

Biochar pHs were measured in duplicate by mixing biochar and deionized water in a 10:1 water:biochar (mL:g) ratio; the resultant slurries were equilibrated for $1 \mathrm{hr}$, and then the $\mathrm{pHs}$ 
were measured by placing a glass $\mathrm{H}^{+}$electrode in the solution just above the settled biochar. Biochar $\mathrm{pH}$ in $\mathrm{NaCl}$ was measured by equilibrating $0.3 \mathrm{~g}$ of each biochar with $15 \mathrm{~mL}$ of $1 \mathrm{M}$ $\mathrm{NaCl}$ for $24 \mathrm{~h}$ on a shaker table. The samples were then filtered to $<0.45 \mu \mathrm{m}$, and the $\mathrm{pH}$ of each $\mathrm{NaCl}$ extract was analyzed (Table 1).

\subsection{Proximate analysis}

Ash, fixed carbon (FC), and volatile matter (VM) of untreated and acid-washed biochars were quantified in triplicate by thermogravimetric analysis using a Mettler TGA/DSC 1 (approach adapted from the standard ASTM method) (Choi et al., 2014). Biochar samples weighing 10-20 $\mathrm{mg}$ were heated to $105^{\circ} \mathrm{C}$ and held at that temperature for $40 \mathrm{~min}$ to remove water. Then samples were heated to $900^{\circ} \mathrm{C}$ in an $\mathrm{N}_{2}$ atmosphere at a rate of $10^{\circ} \mathrm{C} \mathrm{min}^{-1}$; next the temperature was held at $900^{\circ} \mathrm{C}$ for $20 \mathrm{~min}$; and lastly the samples were exposed to air at $900^{\circ} \mathrm{C}$ for $30 \mathrm{~min}$. $\mathrm{VM}$ and $\mathrm{FC}$ were determined as the percentage of mass lost under $\mathrm{N}_{2}$ purge and after exposure to air for 30 min at $900^{\circ} \mathrm{C}$, respectively. Ash content was determined as the percentage of the initial mass remaining after the sample had been exposed to air at $900^{\circ} \mathrm{C}$. To compare the amounts of ash and VM removed during acid washing, the ash and VM contents were normalized to the FC content. The acid-soluble ash was calculated as the difference between FC-normalized ash value of the untreated and acid-washed biochars. Acid-soluble VM was determined similarly. This calculation was based on the assumption that FC is not acid-soluble.

\subsection{Total elemental analysis}

$\mathrm{C}, \mathrm{H}$, and $\mathrm{N}$ of the biochars were determined in triplicate using a Vario Microcube (Elementar) combustion analyzer (Table S1). Additional elements of interest were determined by x-ray fluorescence (XRF) spectroscopy using a Philips PW 2404 X-ray spectrometer (XRF) equipped 
with a rhodium X-ray tube operated at 3600 watts (Lawrinenko et al., 2016). The spectrometer was flushed with helium during all measurements. All measurements were corrected for tube drift by monitoring samples (AUSMON-silicate minerals reference monitor and CA69, a carbonate rock reference monitor). Specimens were presented to the spectrometer as $2 \mathrm{~g}$ of loose powders in disposable sample cups sealed with polypropylene film (6- $\mu \mathrm{m}$ thick). Calibration standards were prepared by spiking a low-ash biochar derived from cellulose slow-pyrolyzed at $700{ }^{\circ} \mathrm{C}$ (prepared in the same manner as slow pyrolysis corn stover biochars) with different percentages of reagent grade potassium chloride and standard reference materials derived from coal ash, minerals and wood (NIST 1633a, NIST 2691, USGS Nod-A-1, NIST 2910, and AWP Std I; see Table S2). These mixtures were combined and co-ground in a SPEX Shatterbox puck mill for two minutes. Due to the similarity between the CE5s and the cellulose biochar used to make the calibration standards, CE5s was excluded from XRF analysis.

\subsection{X-ray diffraction}

X-ray diffraction patterns of four untreated and acid-washed biochars (CS5f, CS3s, CS6s and MW6g) were obtained with an x-ray diffractometer equipped with a graphite monochromator using $\mathrm{Cu} \mathrm{K} \alpha$ radiation generated at $40 \mathrm{KV}$ and $30 \mathrm{~mA}$. Diffracted photons were detected by a scintillation counter in step-scan mode with a step size of $0.05^{\circ} 2 \theta$ and a dwell time of 7 seconds per step. The divergence slit was fixed at $0.5^{\circ}$ and the anti-scatter slit was fixed at $1.5^{\circ}$. Random powder mounts of biochars were analyzed at ambient temperature and humidity. Peaks and corresponding minerals were identified using $\mathrm{JADE}^{\mathrm{TM}} 9.0$ software.

\subsection{Total alkalinity and ion release}


Total alkalinity was quantified by reaction with $\mathrm{HCl}$ and subsequent back titration (Fidel, 2012). This method was previously shown to be effective for use with lignocellulosic biochars, but may need adjustment for use with biochars derived from other feedstocks such as manure. Briefly, the optimal reaction time and $\mathrm{pH}$ were assessed by comparing the amounts of protons accepted and ions solubilized after shaking with $\mathrm{HCl}$ solutions for 2, 4, 8, 16, 24, 48 and 72 hours at $\mathrm{pH}$ of about 1, 2 or 3 from three of the biochars (CE5s, RO5f and CS5f). Biochar was first shaken rapidly on an automatic shaker table with the appropriate $\mathrm{HCl}$ solution at a 50:1 solution:biochar (v:w) ratio. Biochar-solution slurries were then filtered to $<0.45 \mu \mathrm{m}$, and the extracts were titrated to $\mathrm{pH} 8.2$ (phenolphthalein indicator) with standardized $0.05 \mathrm{M} \mathrm{NaOH}$. The $0.05 \mathrm{M} \mathrm{HCl}$ solution was also titrated as a blank. Total alkalinity, expressed as $\mathrm{mmol}$ of $\mathrm{H}^{+}$reacted per gram of air-dry biochar, was calculated from the difference between the amount of acid titrated in the sample and the blank. To quantify elements released during reaction with $\mathrm{HCl}$, triplicate acidic extracts for each biochar were analyzed for $\mathrm{Na}, \mathrm{K}, \mathrm{Ca}, \mathrm{Mg}, \mathrm{Si}, \mathrm{S}, \mathrm{P}, \mathrm{Fe}, \mathrm{Al}$, and $\mathrm{Mn}$ using a Thermo Scientific ${ }^{\mathrm{TM}}$ iCAP ${ }^{\mathrm{TM}} 7400$ ICP-OES Analyzer. The optimal reaction conditions were determined to be 72 hours at $\mathrm{pH} \sim 1.3$ to 2 , and therefore the remaining biochars were equilibrated with $0.05 \mathrm{M} \mathrm{HCl}$ for $72 \mathrm{~h}(1.3 \leq \mathrm{pH} \leq 2)$. Two biochars, HW5s and MW6g, increased the final solution $\mathrm{pH}$ to $>2$, and so these biochars were equilibrated at a 100:1 solution:biochar ratio.

\subsection{Structural and other organic alkalinity}

We define "organic alkalinity" as the equivalents of organic functional groups in biochar that are capable of accepting protons, including both functional groups directly bonded to biochar's condensed aromatic matrix and functional groups in acid-soluble organic compounds. We define "structural alkalinity" as the concentration of such organic functional groups that are directly 
bonded to a biochar's aromatic carbon framework and that are protonated after equilibration with $0.05 \mathrm{M} \mathrm{HCl}$. In principle, the $0.05 \mathrm{M} \mathrm{HCl}$ solution used to quantify total alkalinity should react with all functional groups with $\mathrm{pK}_{\mathrm{a}} \mathrm{s}$ between the $\mathrm{pH}$ of the biochar-equilibrated $\mathrm{HCl}(1.3-2.0)$ and the initial biochar $\mathrm{pH}$ prior to the addition of $\mathrm{HCl}$ (Table 1). The Boehm titration, in which surface functional groups are quantified by equilibration with $\mathrm{NaHCO}_{3}, \mathrm{Na}_{2} \mathrm{CO}_{3}$ and $\mathrm{NaOH}$, is capable of quantifying conjugate acids within discrete $\mathrm{pH}$ ranges defined by the $\mathrm{pK}_{\mathrm{a}} \mathrm{s}$ of the reactants (5-6.4, 6.4-10.3 and 10.3-13, respectively) (Boehm, 1994; Goertzen et al., 2010). Only functional groups with conjugate acid $\mathrm{pK}_{\mathrm{a}} \mathrm{s}$ less than that of the initial biochar $\mathrm{pH}$ are expected to accept protons upon addition of acid to biochar; we therefore refer to conjugate bases of acidic functional groups with $\mathrm{pK}_{\mathrm{a}}<$ biochar $\mathrm{pH}$ as "organic alkalis." However, the lignocellulosic biochars in this study support aqueous-phase pHs ranging from 7.1-10.3, and hence the functional group concentration within the 6.4-to-biochar $\mathrm{pH}$ range cannot be quantified using the Boehm titration. Therefore, we have subdivided "organic alkalis" into the following categories: (1) structural alkalis directly bound to condensed aromatic $\mathrm{C}$ with conjugate acids having $\mathrm{pK}_{\mathrm{a}} \mathrm{s}$ ranging from 5.0 to 6.4 , and (2) other organic alkalis, whose conjugate acids include both functional groups with $\mathrm{pK}_{\mathrm{a}} \mathrm{s}$ between 6.4 and the biochar $\mathrm{pH}$, and soluble organic acids such as acetic or formic acids (Lin et al., 2012; Liu et al., 2015). The other organic alkalis category may also include conjugate bases of weak acids with $\mathrm{pK}_{\mathrm{a}}<5$, and/or condensed aromatic $\mathrm{C}$ itself which may directly adsorb of $\mathrm{H}^{+}$, the latter of which - based on studies of $\mathrm{H}^{+}$sorption by graphite - should be negligible (Boehm, 1994).

Biochar surface functional groups were quantified in triplicate using the integrated "sparge-barium-barium" Boehm titration method developed specifically for biochars by Fidel et al (2013). This method was chosen because it accounts for functional groups with $\mathrm{pK}_{\mathrm{a}}>6.4$ found 
on organic compounds that are soluble in $\mathrm{Na}_{2} \mathrm{CO}_{3}$ and $\mathrm{NaOH}$ (Graber et al., 2016). Briefly, biochars were pre-treated to remove acid-soluble alkalis by washing with $0.05 \mathrm{M} \mathrm{HCl}$, followed by $\mathrm{CaCl}_{2}$ and water. Then the standardized Boehm titration procedure developed by Goertzen et al (2010) was used to quantify functional groups with $\mathrm{pK}_{\mathrm{a}}$ values between 5.0 and 6.4 , or "low$p K_{a}$ structural alkalis." To quantify functional groups with $\mathrm{pK}_{\mathrm{a}} \mathrm{s}>6.4$ and $>10.3,0.05 \mathrm{M} \mathrm{Na}_{2} \mathrm{CO}_{3}$ and $\mathrm{NaOH}$ extracts (respectively) were centrifuged with $\mathrm{BaCl}_{2}$ to remove dissolved organic compounds and carbonates prior to acidification and titration with $\mathrm{NaOH}$ (Fidel et al., 2013). Although functional groups in the higher $\mathrm{pK}_{\mathrm{a}}$ ranges (6.4-10.3 and 10.3-13) were not used to directly quantify other organic alkalis, we quantify them here to give perspective to the determination of other organic alkalis. Other organic alkalis were quantified as the total alkalinity minus the sum of structural alkalis, carbonates $\left(\mathrm{CO}_{3}{ }^{2-}+\mathrm{HCO}_{3}{ }^{-}\right)$, and other inorganic alkalis.

\subsection{Carbonate alkalinity}

Total biochar carbonates $\left(\mathrm{CO}_{3}{ }^{2-}+\mathrm{HCO}_{3}^{-}\right)$were quantified in triplicate using a modified $\mathrm{NaOH}$ trap method (Fidel, 2012). Briefly, $2 \mathrm{~g}$ of each biochar (or $1 \mathrm{~g}$ of HW5s and MW6g, see section 2.6) were stirred with $100 \mathrm{~mL}$ of $0.05 \mathrm{M} \mathrm{HCl}$ in a container placed inside a sealed Mason jar; a separate container inside of the Mason jar held $15 \mathrm{~mL}$ of $1 \mathrm{M} \mathrm{NaOH}$. The $\mathrm{HCl}$ was added using a syringe through a grey butyl septa to ensure no $\mathrm{CO}_{2}$ escaped from the biochar prior to closing the Mason jar. After $72 \mathrm{~h}$, the $\mathrm{NaOH}$ trap was removed, $15 \mathrm{~mL}$ of $1 \mathrm{M} \mathrm{BaCl}_{2}$ were added to the $\mathrm{NaOH}$, and the solution was titrated with $1 \mathrm{M} \mathrm{HCl}$ to $\mathrm{pH} 8.2$ (phenolphalein indicator) to quantify the amount of $\mathrm{CO}_{2}$ evolved from the biochar. 
The quantities of $\mathrm{CO}_{3}{ }^{2-}$ and $\mathrm{HCO}_{3}{ }^{-}$in the total biochar carbonates (determined above) were determined based on the $\mathrm{pH}$ and total carbonate content of $\mathrm{NaCl}$ extracts (see section 2.2). A small aliquot $(0.1$ or $0.2 \mathrm{~mL})$ of each $\mathrm{NaCl}$ biochar extract was pipetted into a $6 \mathrm{~mL}$ Exetainer vial, the headspace was flushed with $\mathrm{He}$ gas, and then $0.1 \mathrm{~mL}$ of $3 \mathrm{M} \mathrm{H}_{3} \mathrm{PO}_{4}$ was added to convert carbonates to $\mathrm{CO}_{2}$. A gas sample from the vial headspace was then analyzed for $\mathrm{CO}_{2}$ using a gas chromatograph. The $\mathrm{CO}_{3}{ }^{2-}: \mathrm{HCO}_{3}{ }^{-}$ratio of the $\mathrm{NaCl}$-soluble carbonates was estimated from the $\mathrm{NaCl}$ extract $\mathrm{pH}$ and the $\mathrm{pK}_{\mathrm{a}}$ of bicarbonate (10.3) using the Henderson-Hasselbach equation. This approach assumes that all $\mathrm{HCO}_{3}{ }^{-}$was soluble in $\mathrm{NaCl}$, and all $\mathrm{NaCl}$-insoluble carbonates were present as $\mathrm{CO}_{3}{ }^{2-}$; thus the $\mathrm{CO}_{3}{ }^{2-}$ content of the biochars was calculated as the difference between total $\mathrm{CO}_{2}$ measured using the $\mathrm{NaOH}$ trap technique and the bicarbonate concentration.

\subsection{Other inorganic alkalinity}

"Other inorganic alkalinity" is here defined as the quantity of protons consumed by acid-soluble inorganic compounds in biochar such as phosphate, sulfate, silicate, iron hydroxides, and aluminum hydroxides. Other inorganic alkalinity was estimated as the sum of P, S, Si, Fe and Al species solubilized during reaction with $0.05 \mathrm{M} \mathrm{HCl}$, in meq $\mathrm{g}^{-1}$. The concentration of each element was converted to $\mathrm{mmol} \mathrm{g}^{-1}$ of the expected alkali specie $\left(\mathrm{PO}_{4}{ }^{3-}, \mathrm{SO}_{4}{ }^{2-}, \mathrm{SiO}_{2}, \mathrm{FeOOH}\right.$, $\mathrm{Al}(\mathrm{OH})_{3}$, etc) (Lindsay, 1979), then converted to meq $\mathrm{g}^{-1}$ based on the $\mathrm{pH}$ of the biochar relative to the $\mathrm{pK}_{\mathrm{a}} \mathrm{s}$ of the alkalis' conjugate acids (Table S3). Our definition of other inorganic alkalinity excludes any inorganic surface functional groups that accepted protons were not solubilized during the reaction with acid; if present in significant quantities, such groups would be included by difference in the "other organic alkalinity" category. 
For biochars with a pHs between 7.1 and 7.3 (RO5f and CS3s), other inorganic alkalinity (in meq $\mathrm{g}^{-1}$ of biochar) was calculated from element concentrations (in brackets) using the equation:

$$
\text { Other inorganic alkalinity }=1.5[\mathrm{P}]+0.5[\mathrm{~S}]+2[\mathrm{Fe}]+3[\mathrm{Al}]
$$

And for biochars with pHs between 7.5 and 9.5 (CS5f, HW5s, and MW6g):

$$
\text { Other inorganic alkalinity }=2[\mathrm{P}]+0.5[\mathrm{~S}]+3[\mathrm{Fe}]+3[\mathrm{Al}]
$$

Lastly, for biochars with pHs between 10.0 and 10.5 (CS5s and CS6s):

$$
\text { Other inorganic alkalinity }=2[\mathrm{P}]+0.5[\mathrm{~S}]+[\mathrm{Si}]+3[\mathrm{Fe}]+3[\mathrm{Al}]
$$

This estimation of other inorganic alkalinity assumes that oxides and hydroxides of base cations - such as $\mathrm{CaO}, \mathrm{KOH}$ or $\mathrm{Mg}(\mathrm{OH})_{2}$ - do not contribute significantly to biochar inorganic alkalinity. Although oxides and hydroxides of base cations have been posited as a hypothetical source of biochar alkalinity, they are not expected to form in appreciable quantities at temperatures lower than $700^{\circ} \mathrm{C}$ (Ar and Doğu, 2001; Galan et al., 2012), and their presence in biochars has not been verified (Keiluweit et al., 2010; Kloss et al., 2012; Lawrinenko and Laird, 2015; Silber et al., 2010; Yuan et al., 2011b). Thus, we consider it unlikely that the biochars analyzed in this study contain significant quantities of oxides or hydroxides of base cations, and we have not included them in our analysis of inorganic alkalis.

\section{Results and Discussion}

\subsection{Evaluation of acid washing and total alkalinity quantification methods}

Kinetics of $\mathrm{H}^{+}$reaction and nutrient release from biochars at varying $\mathrm{pHs}$ was examined to determine the optimal $\mathrm{HCl}$ concentration and reaction time for determination of total alkalinity 
(Figure S1). Equilibration of $0.05 \mathrm{M} \mathrm{HCl}$ with biochar by shaking for 24 to $72 \mathrm{~h}(50 \mathrm{~mL}$ acid:1 $\mathrm{g}$ biochar) consistently yielded the highest total alkalinity upon titration of the resultant extract relative to other $\mathrm{HCl}$ concentrations and equilibration times tested. No significant difference in $\mathrm{HCl}$ consumed was observed between 24 and $72 \mathrm{~h}$ equilibration times. Use of $\mathrm{HCl}$ concentrations less than $0.05 \mathrm{M}$ resulted in lower estimations of total alkalinity due to incomplete reaction of $\mathrm{HCl}$ with biochar alkalis at $\mathrm{pH}>2$. Using higher concentrations of $\mathrm{HCl}$, such as $0.1 \mathrm{M}$ or $1 \mathrm{M}$, also resulted in lower estimates of biochar alkalinity, likely due to the dissolution of acid-soluble alkalis at $\mathrm{pH} \leq 1$ and subsequent interference with the titration of the extracts. Furthermore, we observed that quantities of $\mathrm{CO}_{2}$ evolved were sensitive to $\mathrm{HCl}$ concentration, and therefore recommend using the same concentration of $\mathrm{HCl}$ for total alkalinity and carbonate alkalinity to ensure the measurements are comparable (Figure S2). Therefore, total alkalinity is here defined as the capacity of untreated biochar to accept protons from a $0.05 \mathrm{M}$ $\mathrm{HCl}$ solution $(1.3 \leq \mathrm{pH} \leq 2)$ during a $72 \mathrm{~h}$ equilibration, and carbonate alkalinity is defined as the amount of $\mathrm{CO}_{2}$ evolved during this reaction; both are reported as meq $\mathrm{g}^{-1}$.

To confirm that shaking biochars with $0.05 \mathrm{M} \mathrm{HCl}$ was sufficient to remove crystalline alkali species, select untreated and acid washed biochars (CS5f, CS3s, CS6s, and MW6g) were analyzed using XRD (Figure S3). Following acid washing, XRD peaks attributed to sylvite, calcite, natrite, dolomite, and/or butschliite were either no longer observable or greatly diminished in intensity. The absence of these peaks in suggests that the acid washing procedure removed the majority of soluble, mineral-phase alkalis. Comparison of acid-extractable and total element concentrations revealed that a significant proportion of metals and metalloids are acidinsoluble, likely due to occlusion within insoluble moieties such as quartz, and are therefore unlikely to contribute to total alkalinity. Overall, mineral phases observed in the biochars were 
consistent with literature reports (Kloss et al., 2012; Yuan et al., 2011b). Therefore, we conclude that washing with $\mathrm{HCl}(1.3 \leq \mathrm{pH} \leq 2)$ followed by two $\mathrm{CaCl}_{2}$ washes and four $\mathrm{H}_{2} \mathrm{O}$ washes $(50$ $\mathrm{mL}: 1 \mathrm{~g}$ biochar:solution ratio) is sufficient to remove soluble crystalline alkalis.

\subsection{Total alkalinity}

Total alkalinities varied widely among biochars $\left(0.23-2.70 \mathrm{meq}^{-1}\right)$, with MW6g and CE5s having the highest and lowest total alkalinities, respectively (Figure 1). Slow pyrolysis corn stover biochars exhibited increasing total alkalinity with increasing pyrolysis temperature. Total alkalinity was not significantly correlated with total element concentrations $(\mathrm{C}, \mathrm{H}, \mathrm{N}, \mathrm{S}, \mathrm{P}, \mathrm{Al}$, $\mathrm{Fe}, \mathrm{Mn}, \mathrm{Na}, \mathrm{K}, \mathrm{Ca}$ or $\mathrm{Mg}$ ), any of the proximate analysis metrics (insoluble ash, soluble ash, insoluble VM, soluble VM, or FC), or ratios thereof (Figure S4, Tables S1, S4 and S5). However, total alkalinity was strongly correlated with total equivalents of acid-soluble base cations $\left(r^{2}=0.83\right)($ Figure 2). Furthermore, biochar $\mathrm{pH}$ measured in water increased with increasing total alkalinity and increasing proportions of acid-extractable $\mathrm{K}$ and $\mathrm{Na}$ relative to $\mathrm{Ca}$ and Mg (Tables 1-2 and Figure 1). For example, CS6s had the highest monovalent-to-divalent base cation equivalent ratio (2.5:1), the second highest total alkalinity, and the highest $\mathrm{pH}$; MW6g on the other hand, had the highest total alkalinity but a lower monovalent-to-divalent cation ratio $(0.1: 1)$, and consequently its $\mathrm{pH}$ was lower than $\mathrm{CS} 6 \mathrm{~s}$. Measuring $\mathrm{pH}$ in $1 \mathrm{M} \mathrm{NaCl}$ instead of water did not remove the effect of base cations (Table 1). Thus, among the lignocellulosic biochars examined here, biochar alkalis were predominantly associated with base cations, and higher proportions of acid-soluble monovalent cations among total base cations corresponded with higher biochar $\mathrm{pHs}$. The observed relationship between $\mathrm{pH}$ and total alkalinity demonstrates that $\mathrm{pH}$ should not be used as a proxy for biochar alkalinity, due to the influence of base cations on alkali solubility. 


\subsection{Organic alkalinity}

Boehm titrimetry estimates the concentrations of acidic surface functional groups, which contribute to total alkalinity when their deprotonated conjugate bases accept protons upon exposure of biochars to acid. However, comparison of Boehm titration results with total alkalinity can become problematic because Boehm titrations only quantify functional group concentrations within discrete $\mathrm{pK}_{\mathrm{a}}$ ranges (defined by the conjugate acid $\mathrm{pK}_{\mathrm{a}} \mathrm{s}$ of the reactants $\mathrm{NaHCO}_{3}, \mathrm{Na}_{2} \mathrm{CO}_{3}$ and $\mathrm{NaOH}$ ), whereas total alkalinity includes all sources of alkalinity which are reactive up to the $\mathrm{pH}$ of biochar equilibrated in distilled water (biochar $\mathrm{pH}$ ). Hence, to distinguish surface functional groups which contribute to total alkalinity (conjugate acid $\mathrm{pK}_{\mathrm{a}}<$ biochar $\mathrm{pH}$ ) from those that do not $\left(\mathrm{pK}_{\mathrm{a}}>\right.$ biochar $\left.\mathrm{pH}\right)$, we divide structural alkalinity into two categories: (1) structural alkalinity comprised of surface functional groups having $5.0 \leq \mathrm{pK}_{\mathrm{a}} \leq 6.4$ ("structural alkalis" contributing to "low-pKa structural alkalinity"), and (2) structural alkalinity comprised of organic functional groups with $6.4 \leq \mathrm{pK}_{\mathrm{a}} \leq$ biochar $\mathrm{pH}$. Because the structural functional groups with $6.4 \leq \mathrm{pK}_{\mathrm{a}} \leq$ biochar $\mathrm{pH}$ cannot be distinguished from soluble organic alkalis with conjugate acids having $\mathrm{pK}_{\mathrm{a}} \leq$ biochar $\mathrm{pH}$, these are together considered other organic alkalis.

The majority of biochars had higher low-pKa structural alkalinities than other organic alkalinities. The corn stover biochars tended to have higher low-pK $\mathrm{a}_{\mathrm{a}}$ structural alkalinities compared with wood biochars produced under similar conditions. Slow pyrolysis corn stover biochar pyrolyzed at $300^{\circ} \mathrm{C}$ had a higher structural alkalinity than biochars pyrolyzed at 500$600^{\circ} \mathrm{C}$, demonstrating a pyrolysis temperature effect. Compared with slow pyrolysis biochars, fast pyrolysis biochars had higher low-pK $\mathrm{K}_{\mathrm{a}}$ structural alkalinities, suggesting that heating rate - in addition to pyrolysis temperature - may affect the formation of low-pK $\mathrm{K}_{\mathrm{a}}$ surface functional 
groups. Biochars subject to faster heating rates may have higher structural alkalinities due to a lower extent of feedstock pyrolysis (Brewer et al., 2012, 2009; Sun et al., 2012). Thus both feedstock and pyrolysis conditions affected biochar structural alkalinity, although the effect of temperature appeared non-linear. These low-pK $\mathrm{a}_{\mathrm{a}}$ structural functional groups are of unique importance in that they contribute to long-term soil $\mathrm{pH}$ buffering capacity and CEC in addition to total alkalinity. Indeed, both Amazonian Terra Preta soils and Midwestern Mollisols have been shown to contain high concentrations of carboxylic acids associated with biochar-like black carbon residues, which may be substantial contributors to the organic matter-associated CEC of these soils (Mao et al., 2012).

The biochars pyrolyzed at $600^{\circ} \mathrm{C}(\mathrm{CS} 6 \mathrm{~s}$ and $\mathrm{MW} 6 \mathrm{~g})$ had the largest quantity of other organic alkalis, followed by the corn stover biochars produced at 300 and $500^{\circ} \mathrm{C}$, whereas RO5f, HW5s and CE5s had negligible $\left(\leq 0.02 \mathrm{meq}^{-1}\right)$ quantities of other organic alkalis (Figure 1). All biochars with concentrations of functional groups in the $6.4-10.3 \mathrm{pK}_{\mathrm{a}}$ range $>0.1 \mathrm{meq} \mathrm{g}^{-1}$ and $\mathrm{pH}$ $>7.5$ also had organic alkalinities $>0.1 \mathrm{meq} \mathrm{g}^{-1}$ (Figure S5), suggesting that these functional groups contributed to other organic alkalinity in sufficiently alkaline biochars. Indeed, biochars with $\mathrm{pHs}$ approaching the $\mathrm{pK}_{\mathrm{a}}$ of the $\mathrm{Na}_{2} \mathrm{CO}_{3}$ Boehm reactant (10.3), had functional group concentrations in the 6.4-10.3 $\mathrm{pK}_{\mathrm{a}}$ range $\left(0.25-0.35 \mathrm{meq} \mathrm{g}^{-1}\right)$ approaching their concentrations of other organic alkalis $\left(0.49-0.50\right.$ meq g $\left.^{-1}\right)$. Furthermore, the biochars with $\mathrm{pHs}$ close to the $\mathrm{pK}_{\mathrm{a}}$ of $\mathrm{NaHCO}_{3}(6.4)$ had the lowest quantities of other organic alkalis $\left(<0.05 \mathrm{meq} \mathrm{g}^{-1}\right)$. Other organic alkalinity not accounted for by high-pK $\mathrm{a}_{\mathrm{a}}$ structural functional groups can probably be attributed to soluble organic alkalis such as acetate and formate, which have been previously identified in aqueous biochar extracts (Lin et al., 2012; Liu et al., 2015).

\subsection{Carbonates and other inorganic alkalinity}


The quantities of carbonates $\left(\mathrm{HCO}_{3}{ }^{-}+\mathrm{CO}_{3}{ }^{2-}\right)$ and other inorganic alkalis varied greatly among the eight biochars (Figure 2). Carbonate alkalinity increased with increasing pyrolysis temperature among the slow pyrolysis corn stover biochars (CS3s $<\mathrm{CS} 5 \mathrm{~s}<\mathrm{CS} 6 \mathrm{~s})$, and with increasing divalent cation concentrations among all biochars. The amount of $\mathrm{HCO}_{3}{ }^{-}$in the biochars ranged from 0.01 to $0.27 \mathrm{meq} \mathrm{g}^{-1}$, accounting for 2 to $100 \%$ of carbonate alkalinity; thus $\mathrm{CO}_{2}$ evolved upon acidifying biochar cannot be assumed to originate entirely from one carbonate specie or the other (Table S7).

Concentrations of other inorganic alkalis - here defined as non-carbonate soluble inorganic alkalis and estimated using soluble metal and metalloid concentrations - ranged from 0-0.60 meq g ${ }^{-1}$. Total inorganic alkalinity (carbonate and other inorganic alkalinity) of the slow pyrolysis corn stover biochars increased consistently with increasing pyrolysis temperature $(\mathrm{CS} 3 \mathrm{~s}<\mathrm{CS} 5 \mathrm{~s}<\mathrm{CS} 6 \mathrm{~s})$.

\subsection{Contributions of the various alkalis to total alkalinity}

The contributions of the various alkalis to total alkalinity varied widely with respect to feedstock, pyrolysis temperature and heating rate. The cellulose biochar (CE5s) contained negligible ash (Figure S1) and hence its alkalinity was dominated by structural alkalis ( $87 \%$; conjugate acid $\left.\mathrm{pK}_{\mathrm{a}} 5-6.4\right)$. For the lignocellulosic biochars, however, structural alkalinity ranged from 3 to $49 \%$ of total alkalinity. Other organic and inorganic alkalis consistently contributed $<33 \%$ and $<38 \%$ of the total alkalinity, respectively. Wood biochars consistently had a higher proportion of carbonate alkalinity than corn stover biochars, whereas corn stover biochars consistently had a higher proportion of other (non-carbonate) inorganic alkalinity. When combined, all inorganic alkalis consistently constituted a majority (55-95\%) of lignocellulosic biochars' total alkalinity. Therefore, we conclude that all four categories of biochar alkalinity contribute to biochars' 
capacity to react with acid, and that inorganic alkalis tend to dominate among wood and corn stover biochars.

\subsection{Implications}

We have identified four forms of biochar alkalinity - low- $\mathrm{pK}_{\mathrm{a}}$ structural, other organic, carbonate, and other inorganic alkalinity - and quantified them in eight biochars. These biochars, derived from four feedstocks (cellulose, red oak, mixed wood, and corn stover) and three temperatures $\left(300,500\right.$ and $\left.600^{\circ} \mathrm{C}\right)$, demonstrated a wide range of total alkalinity and diversity of alkali distributions. This diversity allows for development of biochars tailored to specific agricultural and environmental applications, including the amelioration of soil acidity and buffering the $\mathrm{pH}$ of composts and soil-less potting media. Indeed, we anticipate that analysis of biochars not included here, such as those produced from manure or other non-lignocellulosic feedstocks and those produced at different temperatures (such as $350-450^{\circ} \mathrm{C}$, or $>650^{\circ} \mathrm{C}$ ), would reveal an even wider diversity of total alkalinities and distributions. Feedstock, pyrolysis temperature, and other pyrolysis conditions all affected biochar alkalinity and relative proportions of biochar alkalis. Inorganic alkalis consistently constituted the majority of total lignocellulosic biochar alkalinity, emphasizing their importance in $\mathrm{pH}$-sensitive biochar research. Corn stover biochars consistently had higher structural alkalinities than wood biochars, suggesting that corn stover biochars will buffer soil $\mathrm{pH}$ and contribute to CEC more than wood biochars in the long term. However, variability of the impact of pyrolysis conditions and feedstock on biochar alkalinity and alkali composition suggest that biochar alkalinity may arise from complex interactions during production that are difficult to predict solely from pyrolysis parameters. A lack of consistent correlations between VM, FC or ash content and total alkalinity or alkali composition suggests that proximate analysis may be of little use for assessing biochar 
alkalinity. Acid-soluble base cation concentration was an accurate proxy for total alkalinity among the biochars studied here, but this approximating total alkalinity alone does not provide insight into alkali composition or the contribution of biochar to soil $\mathrm{pH}$ buffering capacity or CEC. Total alkalinity and alkali distributions should therefore be directly quantified until the relationship between biochar alkalinity and other biochar properties is better understood.

\section{ACKNOWLEDGMENTS}

Funding for this research was provided by the National Science Foundation under EPSCoR Grant Number EPS-1101284, by Global Climate and Energy Project, Stanford Subaward Agreement No. 640 60413992-112883-A, and by the USDA National Institute of Food and Agriculture under Agriculture and Food Research Initiative Competitive Grant no. 201367011-21156 and under CenUSA Competitive Grant no. 2011-68005-30411.

We thank Tim Parkin, Michael Castellano, and Larry Halverson for their feedback and expertise. We also thank Samuel Rathke for assistance with lab work, Patrick Johnston for assistance with proximate analysis, Ken Moore for assistance with statistical analyses, Catherine Brewer for advice and feedback, and Scott Schlorholtz for assistance with the XRF analysis.

\section{ASSOCIATED CONTENT}

A. Supplementary material. Supplemental Figures S1-S6, Tables S1-S7, in-depth discussion of $\mathrm{XRD}$ results, and comparison of proximate analysis with functional group concentrations can be found online on the Chemosphere website.

\section{REFERENCES}

Ar, İ., Doğu, G., 2001. Calcination kinetics of high purity limestones. Chem. Eng. J. 83, 131137. doi: $10.1016 / \mathrm{S} 1385-8947(00) 00258-8$

Boehm, H.P., 1994. Some aspects of the surface chemistry of carbon blacks and other carbons. 
Carbon N. Y. 32, 759-769. doi:10.1016/0008-6223(94)90031-0

Brewer, C.E., Hu, Y.-Y., Schmidt-Rohr, K., Loynachan, T.E., Laird, D. a., Brown, R.C., 2012. Extent of Pyrolysis Impacts on Fast Pyrolysis Biochar Properties. J. Environ. Qual. 41, 1115. doi:10.2134/jeq2011.0118

Brewer, C.E., Schmidt-Rohr, K., Satrio, J.A., Brown, R.C., 2009. Characterization of biochar from fast pyrolysis and gasification systems. Environ. Prog. Sustain. Energy 28, 386-396. doi:10.1002/ep.10378

Brewer, C.E., Unger, R., Schmidt-Rohr, K., Brown, R.C., 2011. Criteria to Select Biochars for Field Studies based on Biochar Chemical Properties. BioEnergy Res. 4, 312-323. doi:10.1007/s12155-011-9133-7

Cheah, S., Malone, S.C., Feik, C.J., 2014. Speciation of sulfur in biochar produced from pyrolysis and gasification of oak and corn stover. Environ. Sci. Technol. 48, 8474-8480. doi:10.1021/es500073r

Chen, Z., Xiao, X., Chen, B., Zhu, L., 2015. Quantification of Chemical States, Dissociation Constants and Contents of Oxygen-containing Groups on the Surface of Biochars Produced at Different Temperatures. Environ. Sci. Technol. 49, 309-17. doi:10.1021/es5043468

Choi, Y.S., Johnston, P.A., Brown, R.C., Shanks, B.H., Lee, K.-H., 2014. Detailed characterization of red oak-derived pyrolysis oil: Integrated use of GC, HPLC, IC, GPC and Karl-Fischer. J. Anal. Appl. Pyrolysis 110, 147-154. doi:10.1016/j.jaap.2014.08.016

Chun, Y., Sheng, G., Chiou, C.T., Xing, B., 2004. Compositions and Sorptive Properties of Crop Residue-Derived Chars. Environ. Sci. Technol. 38, 4649-4655. doi:10.1021/es035034w

Dai, Z., Wang, Y., Muhammad, N., Yu, X., Xiao, K., Meng, J., Liu, X., Xu, J., Brookes, P.C., 2014. The effects and mechanisms of soil acidity changes, following incorporation of biochars in three soils differing in initial pH. Soil Sci. Soc. Am. J. 78, 1606-1614. doi:10.2136/sssaj2013.08.0340

Fidel, R.B., 2015. Biochar properties and impact on soil CO2 and N2O emissions. Iowa State University.

Fidel, R.B., 2012. Evaluation and implementation of methods for quantifying organic and inorganic components of biochar alkalinity. Iowa State University.

Fidel, R.B., Laird, D.A., Thompson, M.L., 2013. Evaluation of Modified Boehm Titration Methods for Use with Biochars. J. Environ. Qual. 42, 1771-1778. doi: $10.2134 /$ jeq2013.07.0285

Galan, I., Glasser, F.P., Andrade, C., 2012. Calcium carbonate decomposition. J. Therm. Anal. Calorim. 111, 1197-1202. doi:10.1007/s10973-012-2290-X

Goertzen, S.L., Thériault, K.D., Oickle, A.M., Tarasuk, A.C., Andreas, H. a., 2010. Standardization of the Boehm titration. Part I. CO2 expulsion and endpoint determination. Carbon N. Y. 48, 1252-1261. doi:10.1016/j.carbon.2009.11.050

Graber, E.R., Tsechansky, L., Fidel, R.B., Thompson, M.L., Laird, D.A., 2016. Determining Acidic Groups at Biochar Surfaces via the Boehm Titration, in: Singh, B., Camps- 
Arbestain, M., Lehmann, J. (Eds.), Methods of Biochar Analysis. CISRO Publishing, Melbourne.

Joseph, S.D., Camps-Arbestain, M., Lin, Y., Munroe, P., Chia, C.H., Hook, J., Van Zwieten, L., Kimber, S., Cowie, a., Singh, B.P., Lehmann, J., Foidl, N., Smernik, R.J., Amonette, J.E., 2010. An investigation into the reactions of biochar in soil. Aust. J. Soil Res. 48, 501-515. doi:10.1071/SR10009

Keiluweit, M., Nico, P.S., Johnson, M., Kleber, M., 2010. Dynamic molecular structure of plant biomass-derived black carbon (biochar). Environ. Sci. Technol. 44, 1247-1253. doi:10.1021/es9031419

Kloss, S., Zehetner, F., Dellantonio, A., Hamid, R., Ottner, F., Liedtke, V., Schwanninger, M., Gerzabek, M.H., Soja, G., 2012. Characterization of Slow Pyrolysis Biochars: Effects of Feedstocks and Pyrolysis Temperature on Biochar Properties. J. Environ. Qual. 41, 990. doi:10.2134/jeq2011.0070

Laird, D.A., Fleming, P., Davis, D.D., Horton, R., Wang, B., Karlen, D.L., 2010. Impact of biochar amendments on the quality of a typical Midwestern agricultural soil. Geoderma 158, 443-449. doi:10.1016/j.geoderma.2010.05.013

Lawrinenko, M., Laird, D.A., 2015. Anion exchange capacity of biochar. Green Chem. 17, 4628-4636. doi:10.1039/C5GC00828J

Lawrinenko, M., Laird, D.A., Johnson, R.L., Jing, D., 2016. Accelerated aging of biochars: Impact on anion exchange capacity. Carbon N. Y. 103, 217-227. doi:10.1016/j.carbon.2016.02.096

Lehmann, J., Gaunt, J., Rondon, M., 2006. Bio-char Sequestration in Terrestrial Ecosystems - A Review. Mitig. Adapt. Strateg. Glob. Chang. 11, 395-419. doi:10.1007/s11027-005-9006-5

Lin, Y., Munroe, P., Joseph, S., Henderson, R., Ziolkowski, A., 2012. Water extractable organic carbon in untreated and chemical treated biochars. Chemosphere 87, 151-157. doi:10.1016/j.chemosphere.2011.12.007

Lindsay, W.L., 1979. Chemical equilibria in soils. John Wiley \& Sons Inc., New York.

Liu, P., Ptacek, C.J., Blowes, D.W., Berti, W.R., Landis, R.C., 2015. Aqueous Leaching of Organic Acids and Dissolved Organic Carbon from Various Biochars Prepared at Different Temperatures. J. Environ. Qual. 44, 684-695. doi:10.2134/jeq2014.08.0341

Mao, J.-D., Johnson, R.L., Lehmann, J., Olk, D.C., Neves, E.G., Thompson, M.L., SchmidtRohr, K., 2012. Abundant and Stable Char Residues in Soils: Implications for Soil Fertility and Carbon Sequestration. Environ. Sci. Technol. 46, 9571-9576. doi:10.1021/es301107c

McCormack, S.A., Ostle, N., Bardgett, R.D., Hopkins, D.W., Vanbergen, A.J., 2013. Biochar in bioenergy cropping systems: impacts on soil faunal communities and linked ecosystem processes. GCB Bioenergy 5, 81-95. doi:10.1111/gcbb.12046

Pollard, A.S., 2009. Comparison of bio-oil produced in a fractionated bio-oil collection system. Mechnical Eng. Iowa State University.

Pollard, A.S., Rover, M.R., Brown, R.C., 2012. Characterization of bio-oil recovered as stage 
fractions with unique chemical and physical properties. J. Anal. Appl. Pyrolysis 93, 129138. doi:10.1016/j.jaap.2011.10.007

Schimmelpfennig, S., Glaser, B., 2012. One Step Forward toward Characterization: Some Important Material Properties to Distinguish Biochars. J. Environ. Qual. 41, 1001-1013. doi:10.2134/jeq2011.0146

Silber, A., Levkovitch, I., Graber, E.R., 2010. pH-dependent mineral release and surface properties of cornstraw biochar: agronomic implications. Environ. Sci. Technol. 44, 9318 9323. doi:10.1021/es101283d

Simek, M., Cooper, J.E., 2002. The influence of $\mathrm{pH}$ on denitrification: Progress towards the understanding of this interaction over the last 50 years. Eur. J. Soil Sci. 53, 345-354. doi:10.1046/j.1365-2389.2002.00461.x

Singh, B., Singh, B.P., Cowie, A.L., 2010. Characterisation and evaluation of biochars for their application as a soil amendment. Aust. J. Soil Res. 48, 516-525.

Sun, H., Hockaday, W.C., Masiello, C.A., Zygourakis, K., 2012. Multiple controls on the chemical and physical structure of biochars. Ind. Eng. Chem. Res. 51, 3587-3597. doi:10.1021/ie201309r

Tsechansky, L., Graber, E.R., 2014. Methodological limitations to determining acidic groups at biochar surfaces via the Boehm titration. Carbon N. Y. 66, 730-733. doi:10.1016/j.carbon.2013.09.044

Wan, Q., Yuan, J.H., Xu, R.K., Li, X.H., 2014. Pyrolysis temperature influences ameliorating effects of biochars on acidic soil. Environ. Sci. Pollut. Res. 21, 2486-2495. doi:10.1007/s11356-013-2183-y

Wang, T., Camps-Arbestain, M., Hedley, M., Singh, B.P., Calvelo-Pereira, R., Wang, C., 2014. Determination of carbonate-C in biochars. Soil Res. 52, 495-504. doi:10.1071/SR13177

Xu, R., Zhao, A., Yuan, J., Jiang, J., 2012. pH buffering capacity of acid soils from tropical and subtropical regions of China as influenced by incorporation of crop straw biochars. J. Soils Sediments 12, 494-502. doi:10.1007/s11368-012-0483-3

Yuan, J.-H., Xu, R.-K., 2011. The amelioration effects of low temperature biochar generated from nine crop residues on an acidic Ultisol. Soil Use Manag. 27, 110-115. doi:10.1111/j.1475-2743.2010.00317.x

Yuan, J.-H., Xu, R.-K., Wang, N., Li, J.-Y., 2011a. Amendment of Acid Soils with Crop Residues and Biochars. Pedosphere 21, 302-308. doi:10.1016/S1002-0160(11)60130-6

Yuan, J.-H., Xu, R.-K., Zhang, H., 2011b. The forms of alkalis in the biochar produced from crop residues at different temperatures. Bioresour. Technol. 102, 3488-3497. doi:10.1016/j.biortech.2010.11.018 




\section{carbonates}


Characterization and quantification of biochar alkalinity: Figures and Tables

Table 1. Biochar abbreviation, feedstock, pyrolysis temperature, process type, and biochar $\mathrm{pH}$ (in $\mathrm{H}_{2} \mathrm{O}$ and $1 \mathrm{M} \mathrm{NaCl}$ ) expressed as means of two replicates $( \pm 0.1)$.

\begin{tabular}{lccccc} 
Biochar & Feedstock & $\mathbf{T ~}\left({ }^{\circ} \mathbf{C}\right)$ & Process & $\mathbf{p H}\left(\mathbf{H}_{\mathbf{2}} \mathbf{O}\right)$ & $\mathbf{p H}(\mathbf{N a C l})$ \\
\hline CE5s & Cellulose & 500 & Slow pyrolysis & 6.4 & 6.4 \\
RO5f & Red Oak & 500 & Fast pyrolysis & 7.1 & 7.3 \\
CS5f & Corn stover & 500 & Fast pyrolysis & 8.4 & 7.6 \\
CS3s & Corn stover & 300 & Slow pyrolysis & 7.3 & 6.7 \\
CS5s & Corn stover & 500 & Slow pyrolysis & 10.1 & 9.2 \\
CS6s & Corn stover & 600 & Slow pyrolysis & 10.3 & 9.3 \\
HW5s & Hardwood & $\sim 500$ & Slow pyrolysis & 7.9 & 8.2 \\
MW6g & Mixed wood & $\sim 600$ & Gasification & 8.8 & 8.6 \\
\hline
\end{tabular}

$\mathrm{T}=$ highest pyrolysis treatment temperature

Table 2. Concentrations of inorganic elements released from the untreated biochars after $72 \mathrm{hr}$ reaction with $0.05 \mathrm{M} \mathrm{HCl}(\mathrm{n}=3)$.

\begin{tabular}{lccccc}
\hline \multicolumn{7}{c}{ Concentration $\left(\mathbf{g ~ k g}^{-1}\right)$} \\
\hline biochar & Na & K & Mg & Ca & P \\
\hline CE5s & $*$ & $*$ & $*$ & $*$ & $*$ \\
RO5f & 0.32 & 4.6 & 0.38 & 12 & 0.22 \\
CS5f & 0.47 & 18.4 & 4.7 & 15 & 2.8 \\
CS3s & 0.58 & 13.0 & 4.4 & 9.6 & 3.6 \\
CS5s & 0.82 & 24.9 & 4.9 & 12 & 4.3 \\
CS6s & 1.03 & 53.0 & 3.2 & 6.2 & 2.7 \\
HW5s & 0.90 & 2.0 & 0.60 & 23 & 0.29 \\
MW6g & 3.7 & 5.0 & 3.1 & 41 & 0.17 \\
\hline RSD (\%) & 22 & 4 & 17 & 17 & 20 \\
\hline \hline biochar & $\mathbf{S}$ & Si & Mn & Fe & Al \\
\hline & $*$ & $*$ & $*$ & $*$ & $*$ \\
CE5s & 0.05 & 0.59 & 0.05 & 0.09 & $*$ \\
RO5f & 0.29 & 0.86 & 0.09 & 0.38 & 0.17 \\
CS5f & 0.34 & 1.4 & 0.07 & 0.68 & 0.31 \\
CS3s & 0.25 & 1.7 & 0.08 & 0.76 & 0.92 \\
CS5s & 0.11 & 1.8 & 0.10 & 0.00 & 0.18 \\
CS6s & 0.12 & 0.74 & 0.29 & 0.10 & 0.2 \\
HW5s & 0.79 & 5.8 & 0.20 & 0.00 & 0.67 \\
\hline RSD(\%) & 33 & 19 & 13 & 38 & 33 \\
\hline RSD
\end{tabular}

RSD $=$ relative standard deviation

*below detection limit 
Figure 1. Biochar structural (conjugate acid $\left.5 \leq \mathrm{pK}_{\mathrm{a}} \leq 6.4\right)$, other organic, carbonate $\left(\mathrm{HCO}_{3}{ }^{-}+\right.$ $\mathrm{CO}_{3}{ }^{2-}$ ), and other inorganic (non-carbonate) alkalinity in meq per gram of biochar. Error bars represent the standard deviation of the mean $(n=3)$.

Figure 2. Relationship between total soluble base cations (sum of meq $\mathrm{g}^{-1}$ for $0.05 \mathrm{M} \mathrm{HCl}$ extractable $\mathrm{Na}+\mathrm{K}+\mathrm{Ca}+\mathrm{Mg}$ ) and total alkalinity (meq $\mathrm{g}^{-1}$ ) for all eight untreated biochars. Each data point represents the mean of three measurements. Total alkalinity was determined by titration of $0.05 \mathrm{M} \mathrm{HCl}$ extracts.

*In the case of HW5s, total alkalinity was calculated as the sum of carbonate alkalinity, structural alkalinity, and other inorganic alkalinity because carbonate alkalinity $\left(1.47 \mathrm{meq} \mathrm{g}^{-1}\right)$ exceeded the total titratable alkalinity $(1.16$ meq $\mathrm{g}^{-1}$ ). 


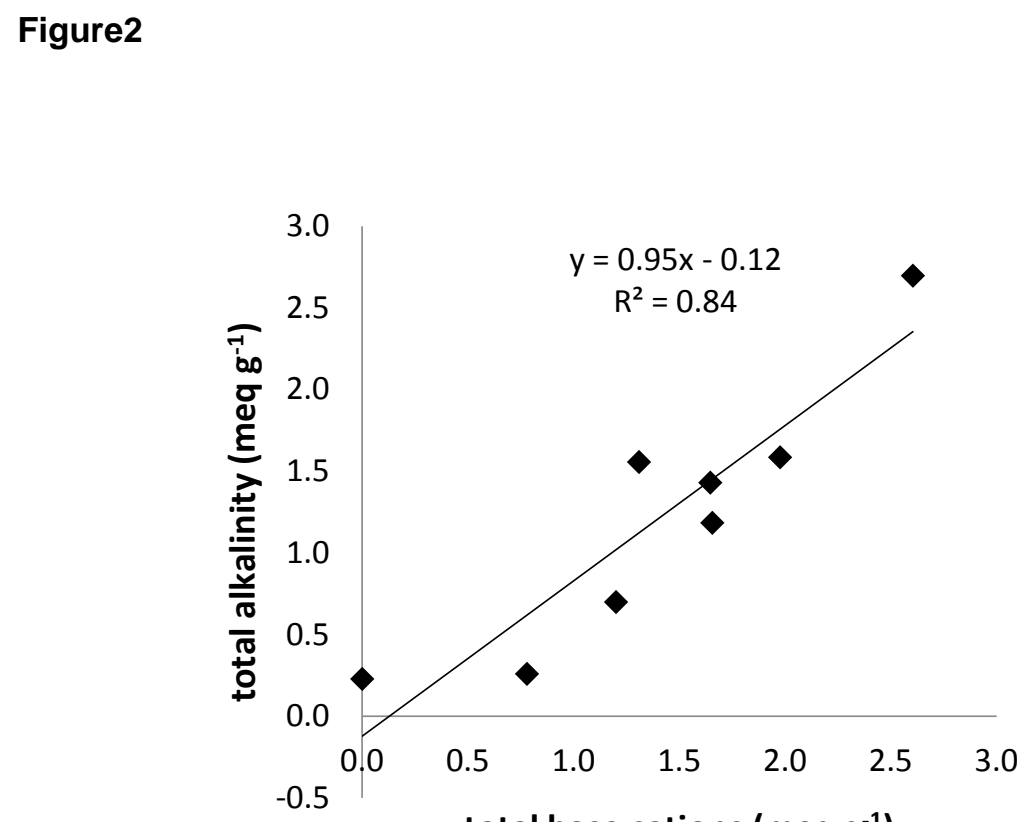

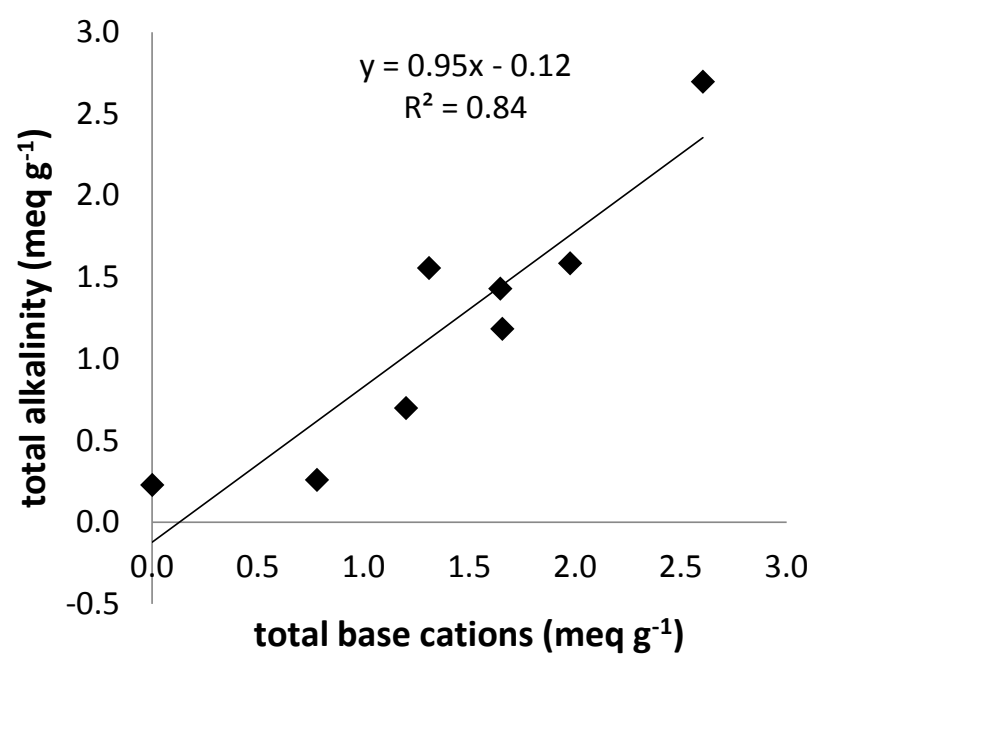
total base cations (meq $\mathrm{g}^{-1}$ )

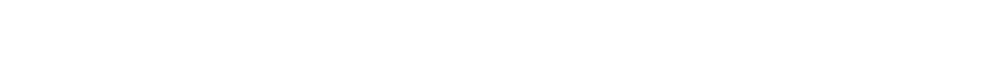

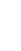

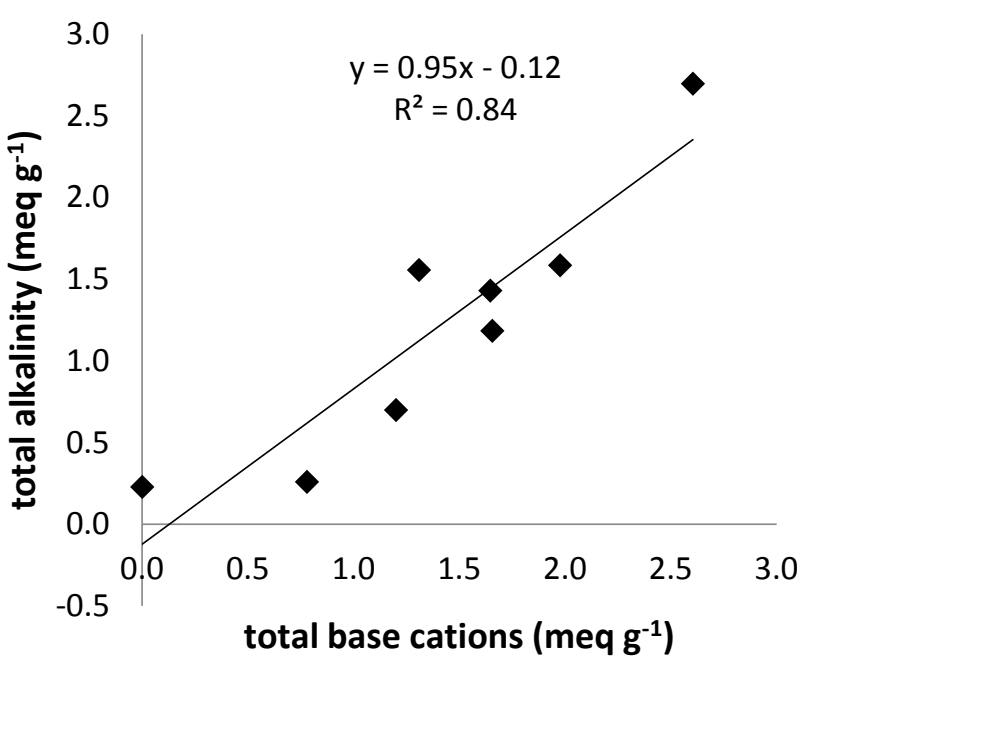

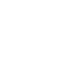

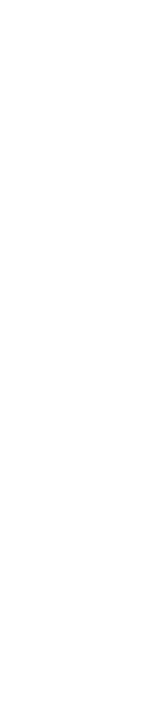


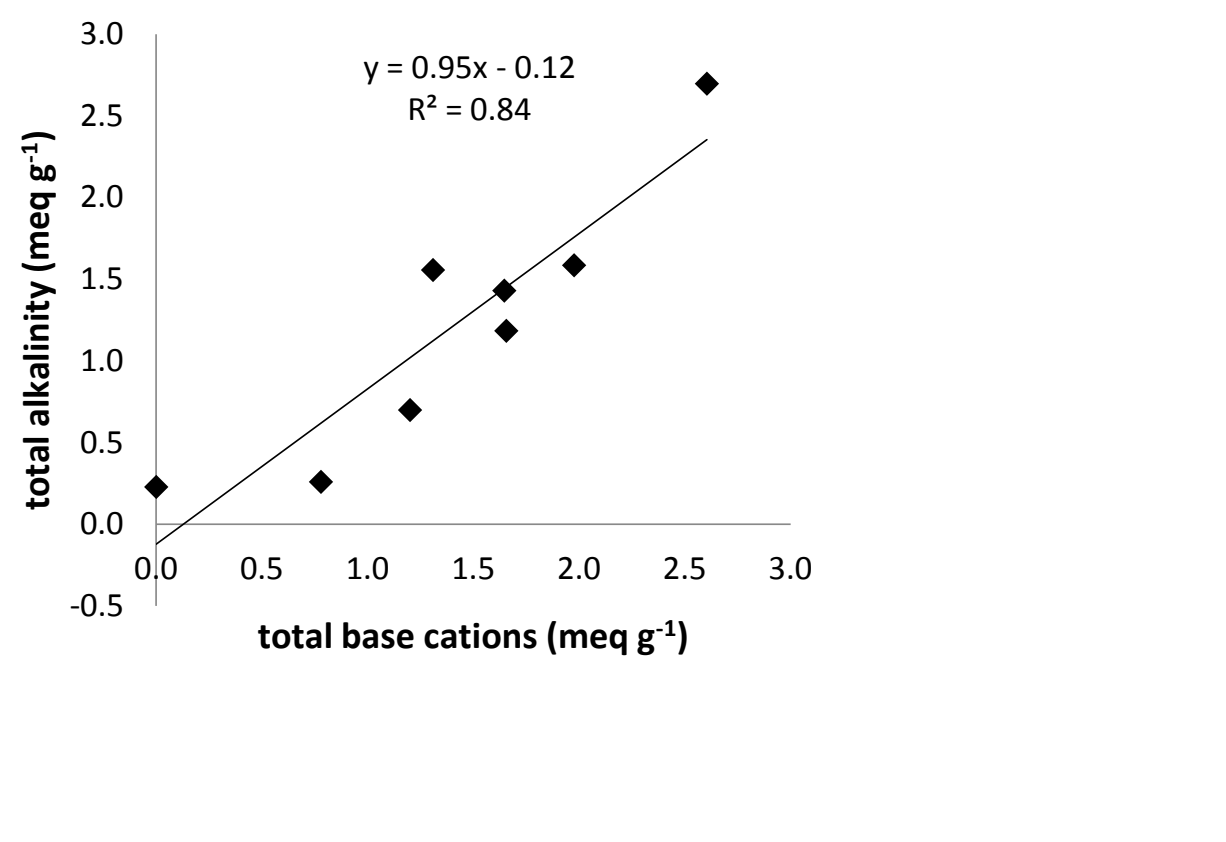